\title{
Cloud Infrastructure at JINR
}

\author{
A. V. Baranov ${ }^{1, a}$, N. A. Balashov ${ }^{1, b}$, N. A. Kutovskiy ${ }^{1,2, c}$, R. N. Semenov ${ }^{1, d}$ \\ ${ }^{1}$ Laboratory of Information Technologies, Joint Institute for Nuclear Research, Joliot Curie 6, \\ Dubna, 141980, Russia \\ ${ }^{2}$ National Scientific and Educational Centre of Particle and High Energy Physics of the Belarusian State Univer- \\ sity, Pervomayskaya Str.18, Minsk, 220040, Belarus \\ E-mail: a baranov@jinr.ru, ${ }^{\mathrm{b}}$ balashov @jinr.ru , ${ }^{\mathrm{c}}$ kut @jinr.ru , ${ }^{\mathrm{d}}$ roman @jinr.ru ,
}

Received September 30, 2014

Cloud technologies are already wide spread among IT industry and start to gain popularity in academic field. There are several fundamental cloud models: infrastructure as a service (IaaS), platform as a service (PaaS), and software as a service (SaaS). The article describes the cloud infrastructure deployed at the Laboratory of Information Technologies of the Joint Institute for Nuclear Research (LIT JINR). It explains the goals of the cloud infrastructure creation, specifics of the implementation, its utilization, current work and plans for development.

Keywords: cloud technologies, virtualization

\section{Облачная инфраструктура ОИЯИ}

\author{
А. В. Баранов ${ }^{1}$, Н. А. Балашов ${ }^{1}$, Н. А. Кутовский ${ }^{1,2}$, Р. Н. Семенов ${ }^{1}$ \\ ${ }^{1}$ Лаборатория информационных технологий, Объединенный институт ядерных исследований \\ Россия, 141980, г. Дубна, ул. Жолио-Кюри, д. 6 \\ ${ }^{2}$ Национальный научно-учебный центр физики частиц и высоких энергий Белорусского государственного \\ университета, Беларусь, 220088, г. Минск, ул. Первомайская, д. 18
}

Облачные технологии широко распространены в ИТ и начинают набирать популярность в научной среде. Существует несколько базовых моделей облачных сред: инфраструктура как услуга (IaaS, англ. Infrastructure-as-a-Service), платформа как услуга (PaaS, англ. Platform-as-a-Service), программное обеспечение как услуга (SaaS, англ. Software-as-a-Service). В данной статье рассматривается облачная инфраструктура, созданная в Лаборатории информационных технологий Объединённого Института Ядерных Исследований (ЛИТ ОИЯИ). Описаны цели создания облачной инфраструктуры, особенности ее реализации, использование, текущие работы и планы по развитию.

Ключевые слова: облачные технологии, виртуализация

Citation: Computer Research and Modeling, 2015, vol. 7, no. 3, pp. 463-467. 


\section{Introduction}

The JINR cloud service was deployed in order to increase an efficiency of the overall IT infrastructure of Laboratory of information technologies functioning: more efficient servers and services management, better hardware utilization, higher services and storage systems reliability. It is built upon an Infrastructure as a Service (IaaS) model. Such model provides network access to computational, software and information resources (networks, servers, storage devices, services and application software), allowing to allocate those resources on-demand according to dynamically changing requirements: cloud users can obtain, configure and deploy VMs themselves with the minimal assistance of the IT specialists. The cloud service is expected to reduce the total cost of ownership of the computing infrastructure as well as to reduce a complexity of its support

\section{Service Implementation}

The JINR cloud service is based on an open-source IaaS system OpenNebula [OpenNebula project, http://opennebula.org]. The two main components of the system can be marked out:

- front-end node (FN): contains the system core and user interfaces to interact with the service;

- cluster nodes (CNs): the physical servers which host the users' virtual machines (VMs).

While CNs are the physical machines, the FN is a virtual one hosted on one of the CNs itself.

Two user interfaces are available to access the service:

- command line interface (CLI);

- web-based graphical user interface "Sunstone".

Figure 1 shows the interactions between the cloud service components.

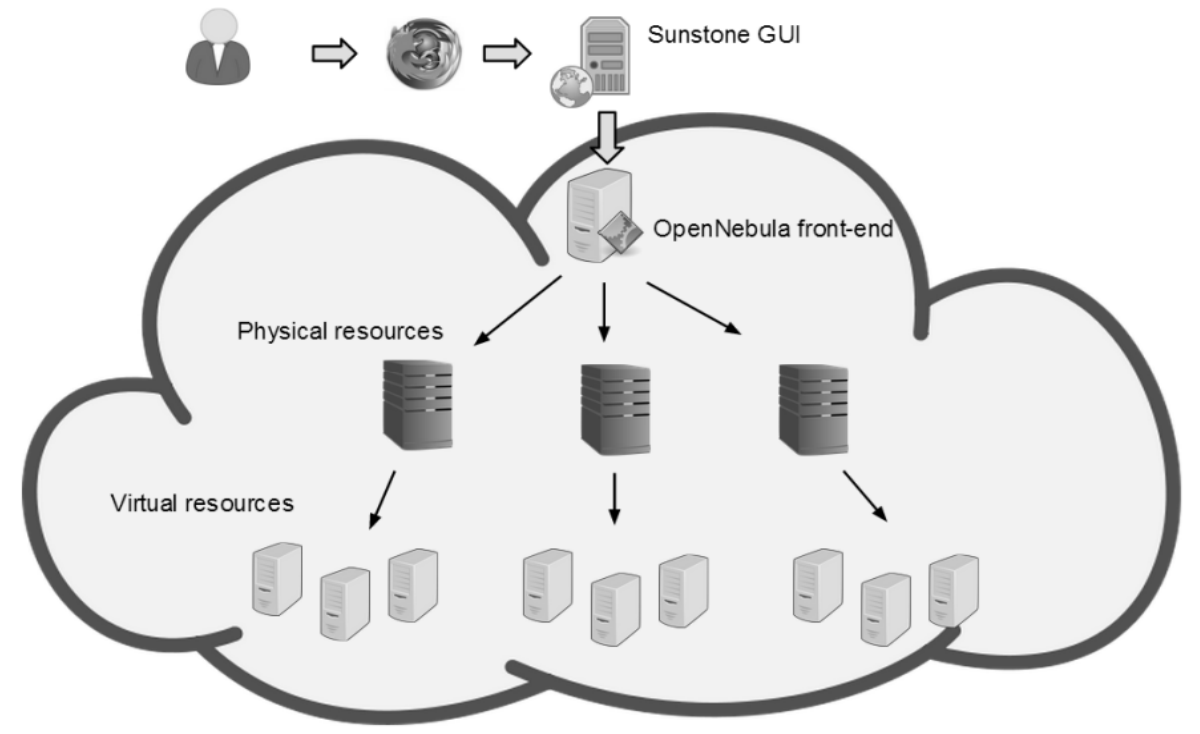

Fig. 1. JINR Cloud service structure scheme showing interactions between its components

Currently the service uses two virtualization technologies to provide VMs:

- OpenVZ [OpenVZ project, http://openvz.org] (an operating system-level virtualization);

- KVM [KVM project, http://www.linux-kvm.org] (provides full hardware virtualization).

The reason why two different virtualization technologies are used is to better utilize hardware resources and at the same time fit the variety of the emerging tasks: OpenVZ containers are lightweight and fast but they are bound to use the hosts operating system kernel, while KVM virtual machines support any type of operating systems inside the VMs but have higher overhead. 
Originally OpenNebula had no OpenVZ containers support but its extensible and modular architecture allowed us to add such support by implementing the custom driver.

JINR cloud service has two types of CNs:

- servers with two mirrored disk drives (RAID1) used to host highly reliable VMs;

- servers with one disk used for educational, research or test VMs.

The virtual machines are monitored currently by Opennebula, some their parameters are tracked by built-in monitoring system and its information is available on the Sunstone dashboard.

To make a request on resources or own quotas extension easily for end-users the custom plugin for Sunstone was developed. It's a simple web-form integrated into Sunstone menu. All that webform's fields need to be filled by user. Pressing "Send" button automatically generates an email to cloud service manager for request approval.

The VMs can be accessed either with use of rsa/dsa-key or password. A plugin implementing Kerberos authentication was developed for user authentication in Sunstone. To increase the security of information exchange between the service web-interface and user's browsers SSL encryption is used.

\section{Service Usage}

Currently the service usage is developed in three directions:

- test, educational and research tasks as part of JINR participation in various projects using cloud and grid technologies;

- systems and services deployment with high reliability and availability requirements;

- increasing computing capacities of the grid-infrastructures during peak loads.

The following services and testbeds are currently deployed in JINR cloud:

- EMI-based [EMI project, www.eu-emi.eu] testbed (used for trainings, performing JINR obligations in international projects such as WLCG [WLCG project, http://wlcg.web.cern.ch], etc);

- ATLAS T3MON [Andreeva et al., 2011] + PanDA [PanDA project, https://twiki.cern.ch/twiki/bin/view/PanDA/PanDA] testbed [Belov et al., 2012] (monitoring tools development for ATLAS Tier-3 sites, PanDA software development for distributed analysis);

- DIRAC-based [DIRAC project, http://diracgrid.org] testbed for BES-III [Web-portal of BES-III experiment, http://bes3.ihep.ac.cn.] experiment (monitoring tools development for BES-III distributed computing infrastructure);

- DesktopGrid testbed (to estimate the volunteer' computing technology for possible use in solving JINR users' tasks);

- web-service HEPWEB (provides a possibility to use different tools for Monte-Carlo simulation in high-energy physics);

- test instances of the JINR document server (JDS) and JINR Project Management Service (JPMS).

Moreover a set of OpenNebula testbeds are deployed in the JINR cloud service for development and debugging OpenVZ driver for current and new OpenNebula software releases. Each of such testbeds consists of 2-3 KVM VMs:

- one FN of test cloud instance,

- 1-2 CNs with OpenVZ hypervisor installed.

Services and testbeds currently deployed in the JINR cloud are shown in figure 2.

\section{Current work and plans}

Current work and features to do are listed below:

- implement authentication in VMs through Kerberos; 
- create a support mailing list to interact with the end-users (to inform them about news, maintenance, new features, etc);

- estimate the possibility to implement Software as a Service (SaaS) model and/or the ability to provide access to virtual machines with pre-installed applications;

- improve quotas request form;

- deploy web-portal containing HOWTOs, FAQs and other information to improve end-users' experience with JINR cloud service.

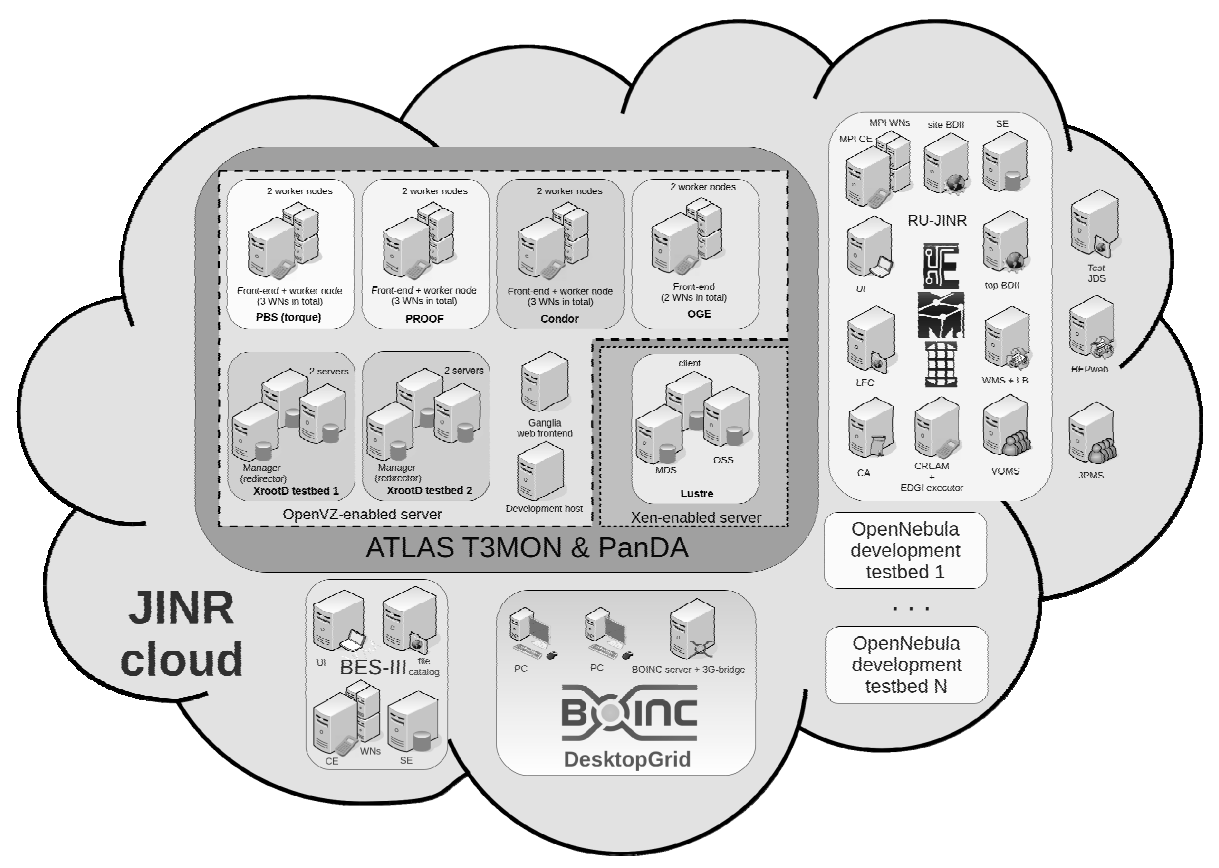

Fig. 2. Services and testbeds currently deployed in the JINR cloud

\section{Conclusions}

The JINR cloud service made possible to better utilize hardware resources. It also significantly simplified the job of system administrators by automating many virtual machines management tasks and by giving the users the ability to create and manage VMs by themselves within the limit of the granted quotas.

The service is actively used to cover users' demands as well as to carry out JINR commitments in Russian and international projects.

OpenNebula platform showed its stability and the ease of use. The source codes and platform architecture occurred to be well designed and easy to understand that makes it flexible and really easy to extend its functionality with custom plugins and drivers.

\section{References}

Andreeva J. et al. Tier-3 Monitoring Software Suite (T3MON) proposal. ATLAS note. - 2011.

Belov S. et al. VM-based infrastructure for simulating different cluster and storage solutions used on ATLAS Tier-3 sites // Journal of Physics: Conference Series. — 2012. — Vol. 396. Part 4. P. 5. doi:10.1088/1742-6596/396/4/042036.

DIRAC project,. URL: http://diracgrid.org.

EMI project. URL: www.eu-emi.eu. 
KVM project. URL: http://www.linux-kvm.org.

OpenNebula project. URL: http://opennebula.org.

OpenVZ project. URL: http://openvz.org.

PanDA project. URL: https://twiki.cern.ch/twiki/bin/view/PanDA/PanDA.

Web-portal of BES-III experiment. URL: http://bes3.ihep.ac.cn.

WLCG project. URL: http://wlcg.web.cern.ch. 